\title{
Effect of different fatty acids on the proliferation and cytokine production of dairy cow peripheral blood mononuclear cells
}

\author{
Noémie Vanacker, ${ }^{1,2}$ Richard Blouin, ${ }^{2}$ Céline Ster, ${ }^{1}$ and Pierre Lacasse ${ }^{1 *}$ (]) \\ ${ }^{1}$ Sherbrooke Research and Development Centre, Agriculture and Agri-Food Canada, Sherbrooke, Quebec, Canada J1M 0C8 \\ ${ }^{2}$ Département de Biologie, Faculté des Sciences, Université de Sherbrooke, Sherbrooke, QC, Canada J1K 2R1
}

\begin{abstract}
During the transition period, dairy cows often experience negative energy balance, which induces metabolic and immunological disturbances. Our previous work has shown a relationship between the inhibition of immune functions and increased blood nonesterified fatty acid (NEFA) levels. In this study, we evaluated the effect of 11 fatty acids (palmitoleic, myristic, palmitic, stearic, oleic, linoleic, docosahexaenoic, conjugated linoleic, lauric, eicosapentaenoic, and linolenic acids) as well as a mix that represented the NEFA profile observed during the transition period at different concentrations $(0,50,100$, and $250 \mu M$ ) on proliferation and cytokines secretion of lymphocytes. To assess lymphoproliferation, peripheral blood mononuclear cell (PBMC) from 5 healthy cows (166-189 d in milk) were isolated, stimulated with the mitogenic lectin concanavalin A (ConA), incubated for $72 \mathrm{~h}$ with or without fatty acids, and subjected to flow cytometry analysis. Our results showed that all fatty acids, except lauric acid, significantly reduced proliferation of PBMC in a dose-dependent manner. The most detrimental effect was observed with conjugated linoleic and stearic acids, where proliferation of PBMC was already inhibited at the lowest dose $(50 \mu M)$. For cytokine secretion, we found that levels of IL-4 in culture supernatant of ConA-stimulated PBMC were reduced after a 24-h exposure to the lowest dose (50 $\mu M)$ of oleic and palmitoleic acids. A dose of $100 \mu M$ of eicosapentaenoic acid, NEFA mixture, and myristic acid was necessary to observe a reduction in IL-4 levels. The PBMC also showed a decrease in the secretion of IFN- $\gamma$ in response to lauric, linolenic, palmitoleic, and stearic acids at $50 \mu M$ and myristic acid at $100 \mu M$. Overall, polyunsaturated fatty acids were more potent inhibitors of cytokine secretions than saturated fatty acids. In addition, we detected an inverse relationship between the melting points of fatty acids and their abil-
\end{abstract}

Received September 15, 2021.

Accepted December 2, 2021.

*Corresponding author: Pierre.Lacasse@agr.gc.ca ity to inhibit IL-4 and IFN- $\gamma$ secretions, as evidenced by greater inhibition with low-melting point fatty acids. Overall, our study confirmed that NEFA have a negative effect on some lymphocyte functions, and that their inhibitory effect on cytokine secretions increases with the degree of unsaturation.

Key words: transition period, immune function, degree of saturation, lymphocyte

\section{INTRODUCTION}

For high-producing dairy cows, the transition from gestation to peak lactation is associated with a high susceptibility to infectious diseases such as mastitis and metritis, likely caused by a state of immunodepression. Indeed, parturition in dairy cattle is associated with a decreased responsiveness of blood lymphocytes to stimulation with mitogenic agents (Carbonneau et al., 2012; Ster et al., 2012; Vanacker et al., 2017) and with decreased immunoglobulin production by B cells (Nonnecke et al., 2003; Lacetera et al., 2005). Accordingly, about $75 \%$ of diseases occur during the first month following calving, and $36 \%$ of deaths occur within the first $60 \mathrm{~d}$ after calving (LeBlanc et al., 2006). Another study of Hammon et al. (2006) showed that there is a relationship between uterine health disorders and the energy status in Holstein cows. Therefore, it is important to determine the causes of periparturient immunodepression to improve the health of dairy cows.

In early lactation, the nutrients provided by the diet are not sufficient to provide the energy required for milk production, resulting in a negative energy balance. Consequently, cows must mobilize fat reserves to balance the energy deficit. A cause-and-effect relationship between energy deficit and the impairment of immune functions was evidenced by Nonnecke et al. (2003). Ster et al. (2012) showed that lymphocyte proliferation and interferon- $\gamma$ secretion were lower when the cells were incubated with sera harvested in the postpartum period and that those parameters were inversely correlated with serum nonesterified fatty acid (NEFA) concentration. In addition, a dose-effect relation- 
ship was found between NEFA concentrations and the inhibition of both lymphocyte proliferation and interferon- $\gamma$ secretion (Lacetera et al., 2004; Ster et al., 2012). These results suggest that the increase in blood NEFA concentration is implicated in the peripartum immunodepression. Accordingly, the odds of developing metritis (Ospina et al., 2010) and mastitis (Moyes et al., 2009) in early lactation increase when the blood NEFA concentration is elevated.

Previous studies have shown an inhibitory effect of different fatty acids on lymphoproliferation (Calder et al., 1990; Calder et al., 1994; Ster et al., 2012). However, the mechanism by which fatty acids affect bovine immune cell functions is still unknown. Calder and Willemsen (2016) suggested that changing immune cell membrane composition can affect the physical properties, the aptitude to form signaling platforms, and the activity of membrane lipid-derived signaling molecules. Indeed, phospholipid membrane functions are strongly involved in the ability of cells to proliferate. Therefore, any change in the fatty acid composition of the membrane lipids has an effect on the proliferative functions. Another way by which NEFA could affect immune function is through the binding and activation of receptors such as the peroxisome proliferator-activated receptor (PPAR).

The results vary considerably among studies evaluating the effect of NEFA on immune functions. These variations can be explained by the wide range of protocols used, including the following: different fatty acids used as either free fatty acid or as an albumin complex, and different concentrations and different exposure times of the T-lymphocyte to the fatty acids. Calder et al. (1991) studied the effect of fatty acids on the proliferation of concanavalin A-stimulated rat lymph node lymphocytes. In general, the effect was dependent on both dose and time of exposure. Unsaturated fatty acids had greater inhibitory power than SFA. To our knowledge, no studies have so far addressed the effect of fatty acids on bovine lymphocyte functions. Because there is a great variability of the responses between species (Tsang et al., 1977), it is important to assess the effect of the fatty acids found in the blood profiles of cows during the peripartum period. Therefore, the aim of this study was to determine the effect of several fatty acids on bovine lymphocyte functions.

\section{MATERIALS AND METHODS}

\section{Reagents}

All fatty acids (palmitoleic acid, myristic acid, palmitic acid, stearic acid, oleic acid, linoleic acid, docosahexaenoic acid, lauric acid, eicosapentaenoic acid, and linolenic acid; Table 1) were purchased from SigmaAldrich Canada Ltd., except for CLA, which was purchased from Cederlane. A NEFA mix containing 36\% stearic acid, $30 \%$ palmitic acid, $25 \%$ oleic acid, $3 \%$ linoleic acid, $2.5 \%$ palmitoleic acid, $2 \%$ myristic acid, and $1.5 \%$ docosahexaenoic acid was prepared. These proportions reflected those encountered in bovine serum during the periparturient period based on different in vivo studies (Leroy et al., 2011; Contreras et al., 2012; Hostens et al., 2012; Watts et al., 2013). Each fatty acid was prepared in a solution of $100 \%$ ethanol to reach a concentration of $100 \mathrm{mM}$ and then stored at $-20^{\circ} \mathrm{C}$ until used. On the day of the experiment, each fatty acid was diluted in RPMI 1640 medium supplemented with $1 \%$ BSA, glutamine, antibiotics, and $1 \%$ ethanol to reach the tested concentration and placed at $37^{\circ} \mathrm{C}$ on agitation for $1 \mathrm{~h}$ before use. The final concentration of ethanol in the wells was $0.25 \%$, and we have previously determined that this concentration of ethanol does not affect the tested parameters.

\section{Animals and Experimental Procedures}

The study was conducted in accordance with the guidelines of the Canadian Council on Animal Care (1993) and approved by Sherbrooke Research and De-

Table 1. Fatty acids used in this study

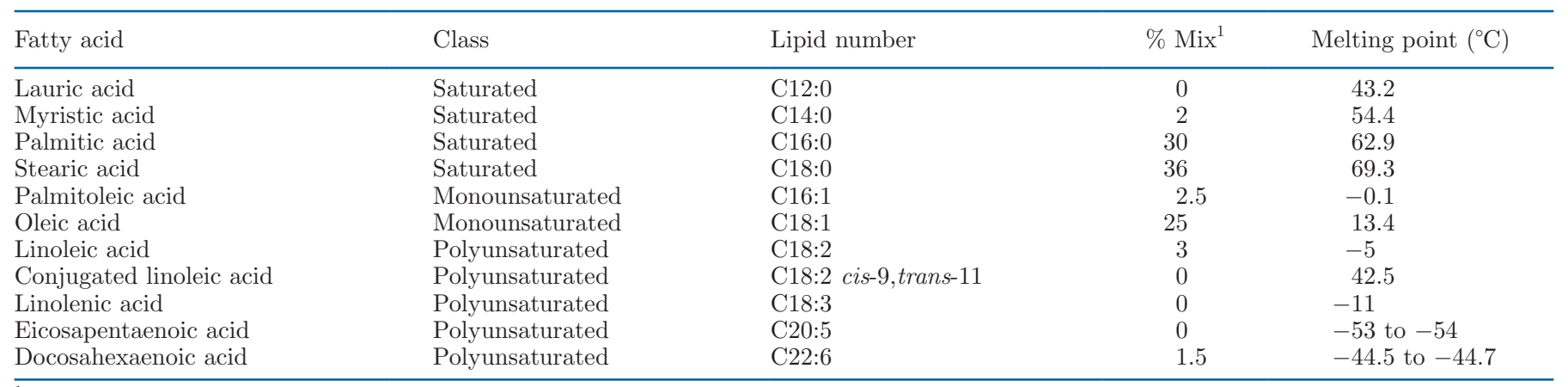

${ }_{1 \%}$ Mix $=$ percentage of each fatty acid used in the mix. 
velopment Centre animal care committee (\#486). Five healthy, multiparous Holstein cows (166-189 DIM, with SCC <240,000/mL) housed at Agriculture and Agri-Food Canada's Sherbrooke Research and Development Centre (Sherbrooke, QC, Canada) were used as immune cell donors. Blood samples were collected from the jugular vein in blood-collection bags containing citrate-phosphate-dextrose-adenine anticoagulant (Animal Blood Resources International). The PBMC were isolated as described by Vanacker et al. (2017). The plasma NEFA concentration for each donor cow was determined by an enzymatic colorimetric method using a Randox kit (Scientifiques ESBE, Saint-Laurent) as previously described by Vanacker et al. (2020). The plasma NEFA concentration was similar in all 5 donor cows, ranging between 210 and $228 \mu M$.

\section{PBMC Proliferation Assay}

Proliferation of PBMC was assayed as described by Ollier et al. (2016), with some modifications. Briefly, isolated PBMC were labeled with $1 \mu M$ carboxyfluorescein diacetate succinimidyl ester using the CellTrace CFSE Cell Proliferation Kit (Thermo Fisher Scientific). To assess the effect of the fatty acid on PBMC proliferation, labeled PBMC were incubated in triplicate within $6 \mathrm{~h}$ after blood collection with the fatty acid of interest or the mix at different concentrations $(0,50,100$, and $250 \mu \mathrm{M})$ and in presence of the mitotic agent concanavalin A (ConA; Sigma-Aldrich) at a concentration of $1 \mu \mathrm{g} / \mathrm{mL}$ in a 96 -well plate $\left(1.5 \times 10^{5}\right.$ cells per well $)$ at $38.5^{\circ} \mathrm{C}$ with $5 \% \mathrm{CO}_{2}$ for $72 \mathrm{~h}$. In each plate, 3 wells were incubated with PBMC stimulated with ConA as positive control, and 3 wells contained PBMC without mitogen stimulation as a negative control. After a 72-h incubation, proliferation was analyzed using the FACSCanto II flow cytometer (BD Biosciences). The number of PBMC recorded was 15,000 .

Before data acquisition, multiple validation tests were done to localize the gates for the dead cells (staining with propidium iodine). These gates were used in the present experiment to evaluate cell death percentage.

\section{PBMC Production of IFN- $y$ and IL-4}

To assess the effect of the fatty acid on PBMC cytokine secretion, PBMC from the same donor cows as for the proliferation assay were incubated with the fatty acid of interest or the mix at different concentrations $(0,50,100$, and $250 \mu M)$ and in presence of the mitotic agent ConA (Sigma-Aldrich) at a concentration of 1 $\mu \mathrm{g} / \mathrm{mL}$ in a 24 -well plate $\left(1.2 \times 10^{6}\right.$ cells per well $)$ at $38.5^{\circ} \mathrm{C}$ with $5 \% \mathrm{CO}_{2}$ for $24 \mathrm{~h}$. The supernatant was then collected by pooling the 2 wells with the same condition and stored at $-80^{\circ} \mathrm{C}$ until measurement. Supernatant cytokine content was determined with commercial kits for each cytokine as follows: IFN- $\gamma$ (Bovine Interferon- $\gamma$ Specific ELISA Assay Kit, Cedarlane Laboratories Limited) and IL-4 (Bovine IL-4 ELISA Kit, RayBiotech Life).

\section{Statistical Analysis}

Because all doses were tested within each of the donor cows, data for percent proliferation were analyzed as a complete block design in a one-way factorial with 4 levels (doses) for each fatty acid separately. Each dose was then compared with the positive control (no fatty acid supplementation and stimulated with ConA) result using a Dunnett adjustment. For the cytokine data, due to variation among cell donor cows, the effect of each dose was tested using a Student's $t$-test on the within-cow delta values calculated between the result at a specific concentration and without added NEFA (n $=5$ ). The fatty acids were separated according to their saturation degree (saturated, monounsaturated, and polyunsaturated), and their average response for each concentration was analyzed with the MIXED procedure of SAS. In addition, regression analysis was performed on the melting point of the fatty acids (Table 1) and the average response using the REG procedure of SAS. Differences were considered significant when $P<0.05$ and were considered a trend when $P<0.10$.

\section{RESULTS}

\section{PBMC Proliferation}

Except for lauric acid $(P>0.1)$, all fatty acids inhibited proliferation within the tested range (Figure 1). The inhibitory effect of CLA and stearic acid was already significant $(P<0.01)$ at the smallest dose tested $(50 \mu M)$. At $100 \mu M$, NEFA mixture, oleic acid, and palmitic acid significantly decreased $(P \leq 0.05)$ PBMC proliferation, whereas eicosapentaenoic acid tended to decrease it $(P=0.06)$. At the highest tested concentration, $250 \mu M$, every fatty acid except for lauric acid significantly decreased lymphoproliferation $(P<0.01)$. No specific effect on the saturation degree $(P>0.5)$ or the melting point $(P \geq 0.2)$ of fatty acids was observed on lymphoproliferation.

Without fatty acids added, cell death ranged between 31.6 and $35.0 \%$. At $50 \mu M$, none of the fatty acids increased cell death (Figure 2). At a concentration of $100 \mu M$, cell death was increased $(P<0.01)$ by CLA and stearic acid. At the highest concentration, CLA, docosahexaenoic acid, NEFA mixture, myristic acid, linolenic acid, oleic acid, palmitic acid, and stearic acid 
significantly increased cell death $(P \leq 0.05)$, whereas eicosapentaenoic acid and linoleic acid tended $(P<$ $0.1)$ to increase it. Lauric acid and palmitoleic acid did not increase $(P>0.4)$ cell death at any of the doses tested.

\section{Cytokine Secretion}

Concentrations of IFN- $\gamma$ in the supernatant of PBMC incubated without ConA were very low and below the detection limit of the test (not shown). Without NEFA added to the medium, stimulation of PBMC with ConA induced a secretion of IFN- $\gamma$ (value $\pm \mathrm{SE} ; 3,220$ $\pm 641 \mathrm{pg} / \mathrm{mL}$ ). At a concentration of $50 \mu M$, lauric acid, linolenic acid, palmitoleic acid, myristic acid, and stearic acid significantly decreased IFN- $\gamma$ secretion $(P$ $\leq 0.05)$ when compared with that observed in cells incubated without fatty acids (Table 2). At this same concentration, CLA, eicosapentaenoic acid, and linoleic acid tended to decrease the levels of IFN- $\gamma$ in the supernatant $(P<0.1)$. Furthermore, at a concentration of $100 \mu M$, the NEFA mixture, lauric acid, linolenic acid, and myristic acid significantly decreased IFN- $\gamma$ secretion $(P \leq 0.05)$, whereas all the other fatty acids except for stearic acid and oleic acid tended to decrease it $(P<0.1)$. On the contrary, palmitic acid tended to increase IFN- $\gamma$ secretion $(P<0.1)$. Oleic acid as well as stearic acid had no effect on IFN- $\gamma$ secretion. At the highest concentration, no significant changes were observed; however, eicosapentaenoic acid, lauric acid, myristic acid, linolenic acid, and palmitoleic acid tended to decrease IFN- $\gamma$ secretion $(P<0.1)$. We observed that PUFA were more potent inhibitors of IFN- $\gamma$ secretion than SFA $(P \leq 0.05)$ at all concentrations (Figure 3). Similarly, the inhibitory effect of fatty acid on IFN- $\gamma$ production increased when the melting point of the fatty acids decreased $(P \leq 0.05)$. Polyunsaturated fatty acids were more inhibitory than SFA at 50 $\mu M(P=0.02), 100 \mu M(P=0.05)$, and $250 \mu M(P=$ $0.03)$. Monounsaturated fatty acids tended to be more inhibitory than SFA at $50 \mu M(P=0.07)$.

Concentration of IL-4 in the supernatant of PBMC incubated without ConA were very low and below the detection limit of the test (not shown). Without NEFA

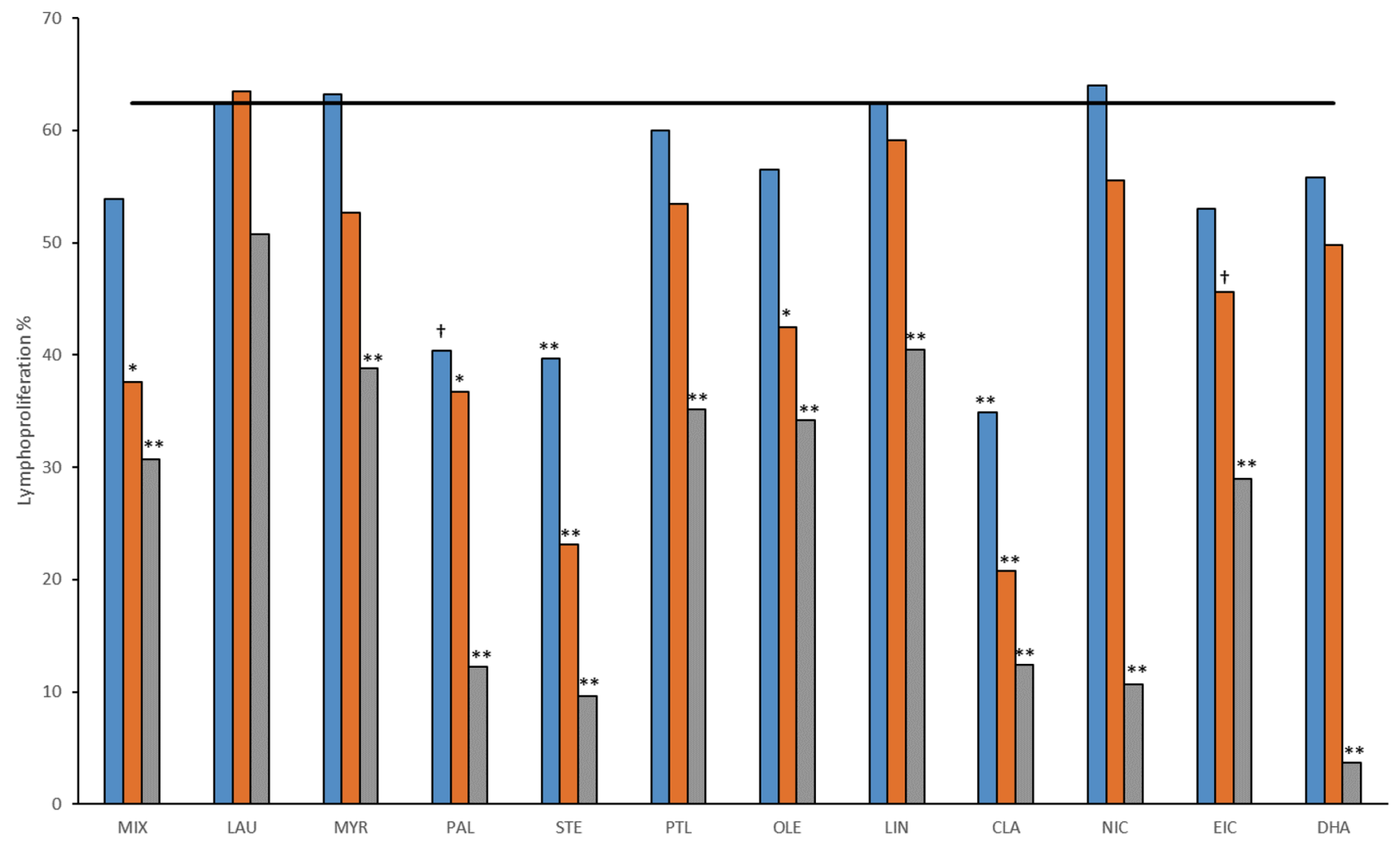

Figure 1. Percentage of lymphoproliferation in the presence of fatty acids at different concentrations (blue $=50 \mu M$; orange $=100 \mu M$, and gray $=250 \mu M$ ) compared with untreated control (horizontal line; ${ }^{*} P<0.01 ;{ }^{*} P<0.05 ; \dagger P<0.1$ ); SEM $\leq 10.5$. MIX $=$ mix of nonesterified fatty acids; LAU = lauric acid; MYR = myristic acid; PAL = palmitic acid; STE = stearic acid; PTL = palmitoleic acid; OLE = oleic acid; LIN $=$ linoleic acid; NIC = linolenic acid; EIC = eicosapentaenoic acid, DHA = docosahexaenoic acid. 


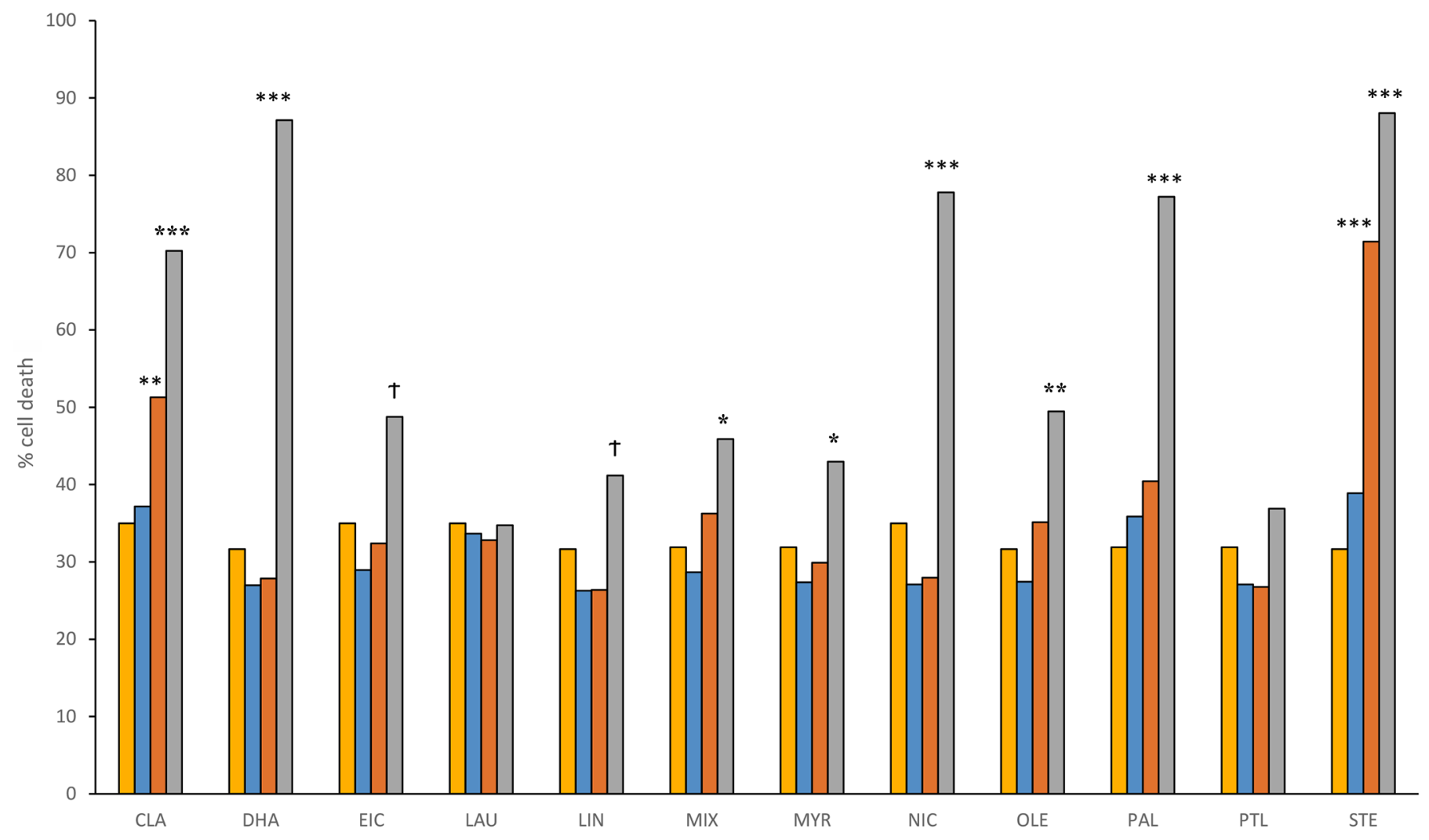

Figure 2. Percentage of cell death during the lymphoproliferation in either absence (yellow $=0 \mu \mathrm{M}$ ) or presence of fatty acids at different concentrations (blue $=50 \mu M$; orange $=100 \mu M$, and gray $=250 \mu M ; * * * P<0.001 ;{ }^{*} P<0.01 ; * P<0.05 ; \dagger P<0.1$ ); SEM $\leq 5.6$. DHA $=$ docosahexaenoic acid; EIC = eicosapentaenoic acid; LAU = lauric acid; LIN = linoleic acid; MIX = mix of nonesterified fatty acids; MYR = myristic acid; NIC = linolenic acid; OLE = oleic acid; PAL = palmitic acid; PTL = palmitoleic acid; STE = stearic acid.

added to the medium, stimulation of PBMC with ConA induced a secretion of IL-4 $(2,207 \pm 366 \mathrm{pg} /$ $\mathrm{mL}$ ). At a concentration of $50 \mu \mathrm{M}$, oleic acid, myristic acid, and palmitoleic acid significantly decreased IL-4 secretion $(P \leq 0.05)$ when compared with the control (Table 3). At $100 \mu M$, NEFA mixture, myristic acid, palmitoleic acid, oleic acid, linolenic acid, and eicosapentaenoic acid significantly decreased IL-4 secretion $(P \leq 0.05)$, whereas lauric and linoleic acids tended to decrease it $(P<0.1)$. At the highest concentration, NEFA mixture, myristic acid, palmitoleic acid, and oleic acid significantly decreased IL-4 secretion $(P \leq$ $0.05)$, whereas all other fatty acids except for palmitic acid and stearic acid tended to decrease it $(P<0.1)$. Stearic acid was the only fatty acid showing no effect on IL-4 secretion at all doses tested. At a concentration of $250 \mu M$, we observed that PUFA tended to be inhibitors of IL-4 secretion $(P=0.09$; Figure 4$)$. At the concentrations of 50 and $100 \mu \mathrm{M}$, the inhibitory effect of fatty acids on IL- 4 production tended to increase when the melting point of the fatty acid decreased $(P<$ 0.1 ). At a concentration of $250 \mu M$, that effect became significant $(P<0.01)$.

\section{DISCUSSION}

The mix of NEFA had an effect on lymphocyte functions at a concentration of $100 \mu M$, which is much lower than the concentration observed during the periparturient period, when blood concentrations can reach up to $700 \mu M$ (Adewuyi et al., 2005; McCarthy et al., 2015). In vivo, most NEFA are complexed to BSA. Although BSA was added to the cell medium, its concentration in the well $(0.25 \%)$ was low in comparison to its concentration in the bloodstream (3\%; Labouche, 1964). Therefore, for the same concentration, the amount of free fatty acid available is likely to be higher in vitro compared with in vivo, which could explain the biological effects observed in vitro with lower doses. The negative effect of the NEFA mix on lymphoproliferation showed that the model chosen for this assay was adequate. The results supported the concept that NEFA have a role in the impairment of the immune system during the periparturient period.

In the present study, most fatty acids inhibited IL-4 and IFN- $\gamma$ secretion. Although they reported an inhibitory effect of fatty acids on bovine PBMC proliferation, 

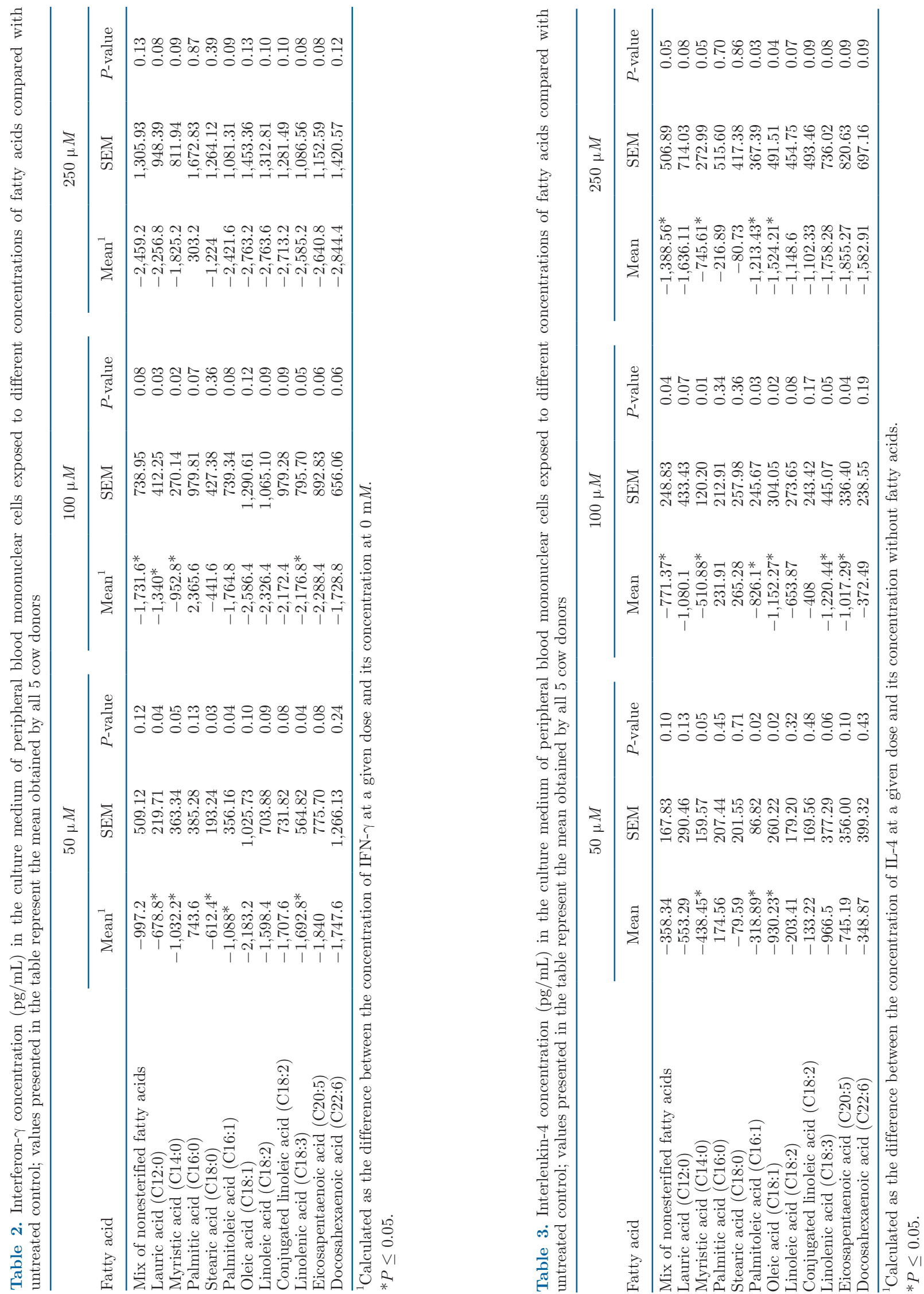
Renner et al. (2013) did not report an effect of fatty acids on IL- 4 and IFN- $\gamma$. The difference observed between their study and ours is likely related to the methodology used. Indeed, we measured cytokine secretion in the culture supernatant using ELISA tests, whereas Renner et al. (2013) measured cytokine gene expression in the PBMC after $72 \mathrm{~h}$ of incubation by real time reverse transcription-PCR. The effect that could have been observed in cytokine secretion might have been mitigated by the long incubation. In addition, the ELISA method is a direct measurement of the cytokine concentration present in the supernatant, whereas the amount of RNA doesn't equal the amount of protein that is actually translated (Alberts et al., 2002; Al-Ali and González-Sarmiento, 2016)

Inhibition of cytokine secretion was greater for PUFA than for SFA. Similarly, studies have reported that PUFA were more effective inhibitors of rat lymphocyte functions than SFA (Calder et al., 1990). Because phospholipids are the main component of the cell membrane (Nicolson, 2014), a change in the fatty acid composition alters its biophysical properties. Calder et al. (1994) showed that by adding fatty acids to the medium, the fatty acid composition and the membrane fluidity were changed. They found that long-chain SFA decreased membrane fluidity, whereas UFA increased it. Calder and Willemsen (2016) have proposed that those changes in membrane fluidity could be responsible for the inhibition of lymphocyte functions. In support of this hypothesis, the regression analysis of our results showed an inverse relationship between the melting point and the ability to inhibit IL- 4 and IFN- $\gamma$ secretions. Nevertheless, the inhibitory activity of CLA, a PUFA with a relatively high melting point, was not clearly lower than that of linoleic acid, which has the same chemical composition but a much lower melting point. Fan et al. (2003) showed that PUFA changed lipid raft composition, soluble membrane phospholipids, and fatty acyl composition, which could lead to a modulation of T-cell activation. Lipid rafts are specialized plasmamembrane microdomains containing high concentrations of cholesterol and sphingolipid, and their polar lipids are predominantly formed of saturated fatty acyl residues (Martins de Lima et al., 2007). Lipid rafts are important in signal transduction pathways such as the T-cell receptor pathway, which is indirectly involved in the regulation of T-cell functions such as proliferation, differentiation, death, and cytokine release. Therefore, a change in their composition could explain the negative effect of fatty acids observed on IL- 4 and IFN- $\gamma$

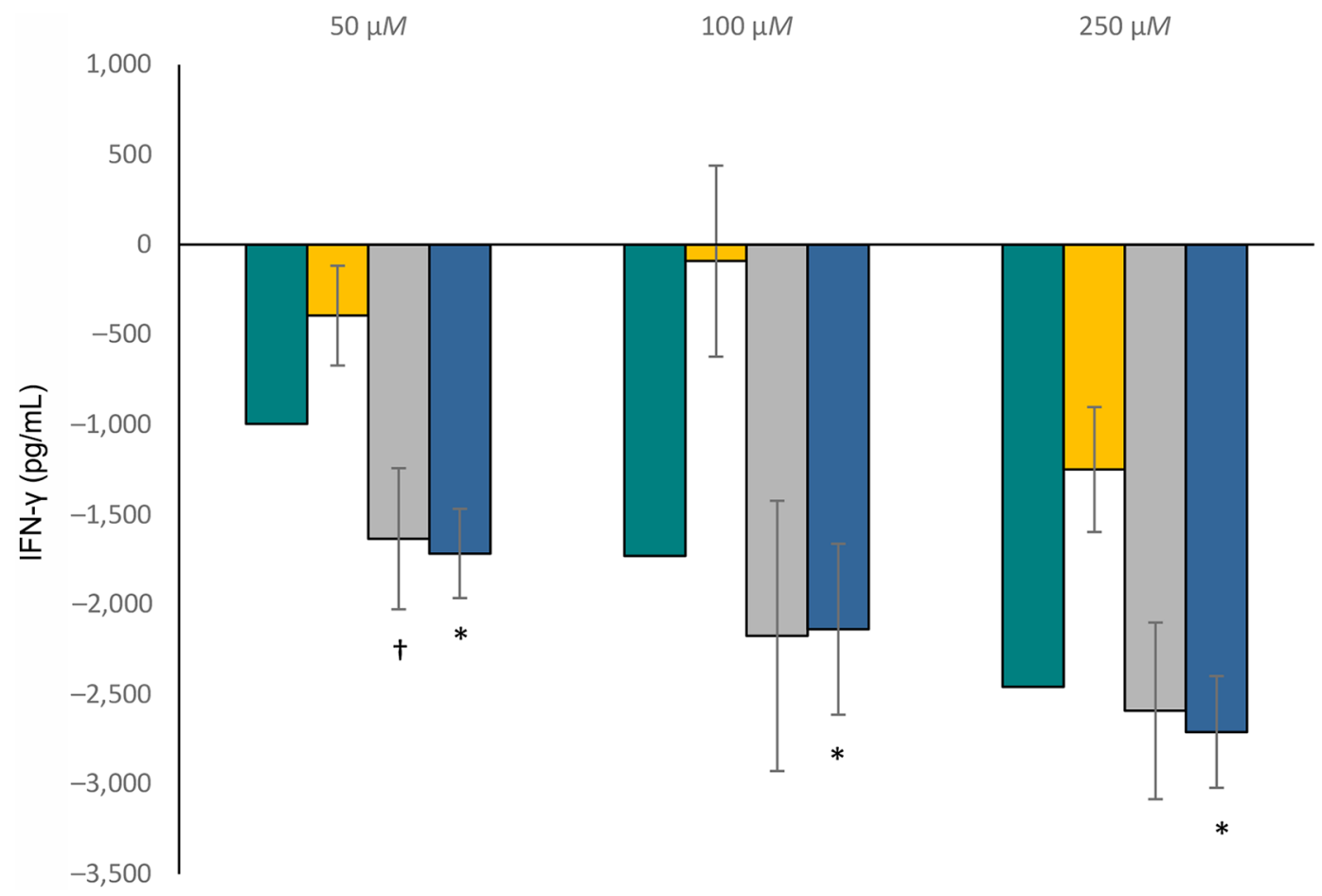

Figure 3. Mean value $\pm \mathrm{SE}$ of IFN- $\gamma$ production according to the class of nonesterified fatty acids (green $=$ mix of nonesterified fatty acids, yellow $=$ saturated, gray $=$ monounsaturated, blue $=$ polyunsaturated $)$, calculated as the difference between the concentration of IFN- $\gamma$ at a given dose and its concentration without fatty acids. Polyunsaturated fatty acids were more inhibitory than saturated fatty acids at $50 \mu M(P$ $=0.02), 100 \mu M(P=0.05)$, and $250 \mu M(P=0.03)$. Monounsaturated fatty acids tended to be more inhibitory than saturated fatty acids at $50 \mu M(P=0.07) .{ }^{*} P<0.05 ; \dagger P<0.1$. 


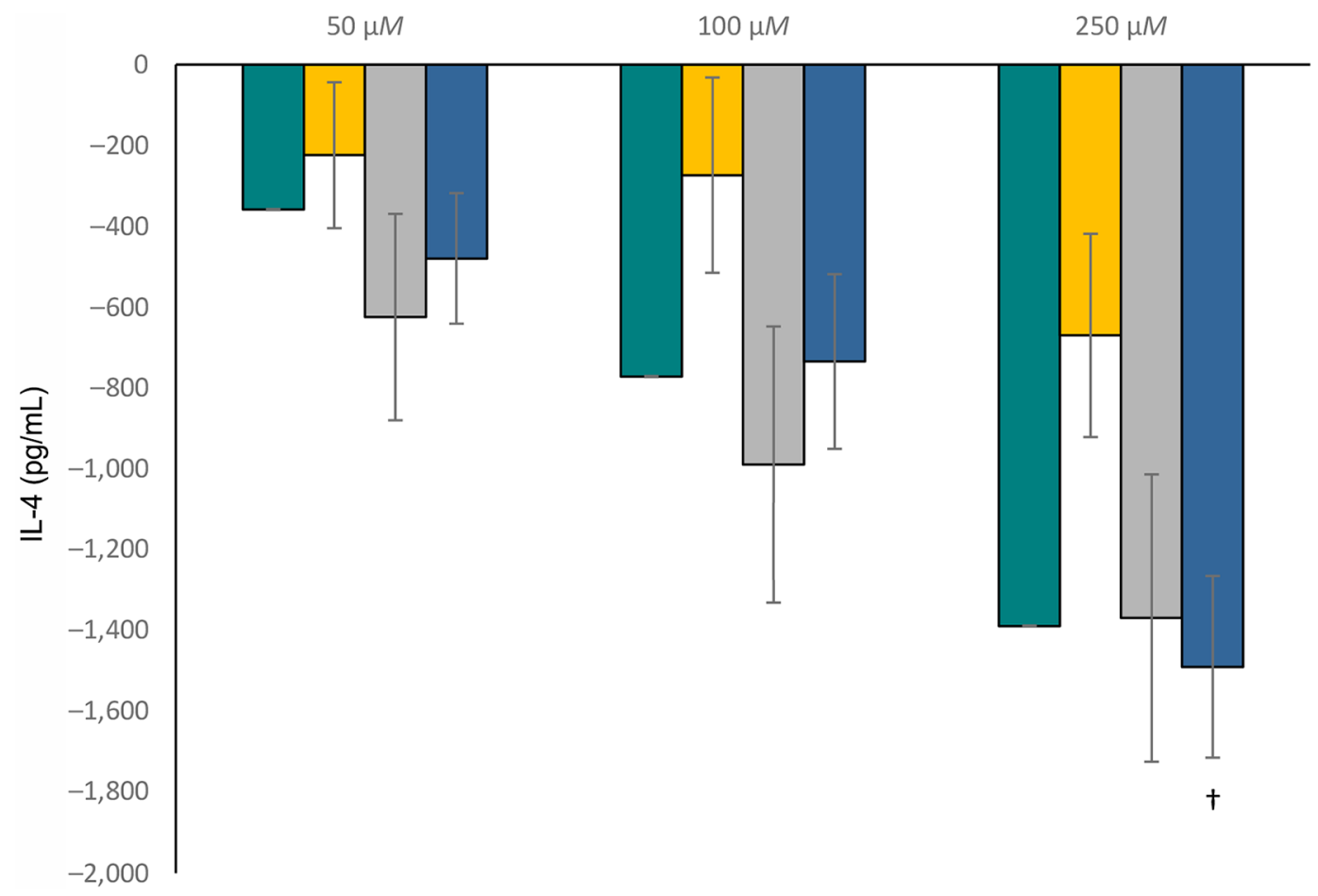

Figure 4. Mean value \pm SE of IL-4 production according to the class of nonesterified fatty acids (Green = mix of nonesterified fatty acids, yellow $=$ saturated, gray $=$ monounsaturated, blue $=$ polyunsaturated $)$, calculated as the difference between the concentration of IL- 4 at a given dose and its concentration without fatty acids. Polyunsaturated fatty acids tend to be more inhibitory than saturated fatty acids at $250 \mu M(P$ $=0.09) . \dagger P<0.1$.

production. We also found that stearic and palmitic acids were potent inhibitors of proliferation but had less effects on the inhibition of cytokine secretions, indicating that although membrane fluidity may affect lymphocyte functions, other mechanisms are also probably involved.

We found a negative dose-dependent effect of all fatty acids, except lauric acid, on lymphoproliferation. Accordingly, Ster et al. (2012) showed that NEFA had a negative effect on lymphoproliferation, oxidative burst, and IFN- $\gamma$ production. Additionally, Calder et al. (1990) studied the effect of different fatty acids on the proliferation of ConA-stimulated rat lymph node lymphocytes. They concluded that all tested fatty acids inhibited mitogen response, and the extent of the inhibition was dependent on the fatty acid concentration. However, unlike Calder et al. (1990), we did not observe a link between the chain length or the saturation degree and the inhibitory activity of fatty acids on lymphoproliferation. Indeed, lymphoproliferation is inhibited by docosahexaenoic acid, a long PUFA, and by myristic acid, a short-chain SFA. Tsang et al. (1977) showed that the effect of fatty acids on lymphoproliferation differs between species. For example, in humans, there is no inhibition when cells are exposed to a mixture contain- ing SFA and UFA. In ewes, oleic, stearic and palmitic acids inhibit proliferation of PBMC, but linoleic and palmitoleic acids did not (Lacetera et al., 2002). Studies have shown that fatty acids can even stimulate the proliferation of phytohemagglutinin-stimulated lymphocytes when using a combination of palmitate and oleate in rats. Therefore, it was not unexpected that results obtained with bovine cells were different from those obtained previously with rodent and human cells.

Our results did not show that a specific class of fatty acids was more potent at inhibiting lymphoproliferation, suggesting that other mechanisms may be involved. One possibility is activation of PPAR, a nuclear receptor that exists in 3 different isoforms, $\alpha, \beta$, and $\gamma$. Each isoform is differentially expressed in diverse tissues and cell types, and regulates the transcription of genes implicated in metabolism, cell proliferation, differentiation inflammation control, and immune responses (Le Menn and Neels, 2018). A large variety of ligands, including UFA, lipids, and lipid-like molecules, are capable of binding the PPAR ligandbinding domain (Grygiel-Górniak, 2014). Peroxisome proliferator-activated receptor- $\gamma$ has notably been demonstrated to impair T-cell proliferation in humans and mice. Although there is no direct evidence that PPAR 
are involved in NEFA-induced inhibition of bovine lymphocyte functions, we found that docosahexaenoic acid and eicosapentaenoic acid, 2 known natural ligands of PPAR- $\gamma$, reduced lymphoproliferation in bovine cells.

The mechanisms causing immunodepression in cows during the periparturient period are diverse and complex. A better understanding of these mechanisms requires studies examining different parameters, such as immune function, fatty acid concentrations, and time of exposure, all of which can affect the results. Indeed, we cannot clearly identify a class of fatty acid for its negative effect on every immune function tested. However, the polyunsaturated class appears to be more detrimental, and the melting point seems to play a role. It is possible that changes in the physiological composition of the NEFA blood profile cause an imbalance, which then leads to immune function deficiencies. Overall, our study confirmed that NEFA individually have a negative effect on the tested parameters and that their inhibitory effects on cytokine secretions increases with the degree of unsaturation.

\section{ACKNOWLEDGMENTS}

The authors thank the following people from Agriculture and Agri-Food Canada (Sherbrooke, QC, Canada): Catherine Thibault, Henrique Hooper, Clémence Bitu, Marie-Pascale Morin, Samantha Bennett, and Samuel Lanctôt for providing technical assistance; Steve Méthot for helping with statistical analyses; and the dairy barn staff for taking care of the animals. This research was financially supported by the Canadian Bovine Mastitis Research Network (Saint-Hyacinthe, QC, Canada), Agriculture and Agri-Food Canada (Ottawa, ON, Canada), Dairy Farmers of Canada (Ottawa, ON, Canada), and the Natural Sciences and Engineering Research Council of Canada (Ottawa, ON, Canada). Noémie Vanacker received a scholarship from Natural Sciences and Engineering Research Council of CanadaCREATE on milk quality. The authors have not stated any conflicts of interest.

\section{REFERENCES}

Adewuyi, A. A., E. Gruys, and F. Van Eerdenburg. 2005. Non esterified fatty acids (NEFA) in dairy cattle. A review. Vet. Q. 27:117126. https://doi.org/10.1080/01652176.2005.9695192.

Al-Ali, R., and R. González-Sarmiento. 2016. Proximity of AUG sequences to initiation codon in genomic $5^{\prime}$ UTR regulates mammalian protein expression. Gene 594:268-271. https://doi.org/10 $.1016 /$ j.gene.2016.08.052.

Alberts, B., A. Johnson, J. Lewis, M. Raff, K. Roberts, and P. Walter. 2002. From RNA to Protein. Molecular Biology of the Cell. 4th edition. Garland Science.

Calder, P. C., J. A. Bond, S. J. Bevan, S. V. Hunt, and E. A. Newsholme. 1991. Effect of fatty acids on the proliferation of concana- valin A-stimulated rat lymph node lymphocytes. Int. J. Biochem. 23:579-588. https://doi.org/10.1016/0020-711X(87)90052-8.

Calder, P. C., J. A. Bond, and E. A. Newsholme. 1990. Fatty acid inhibition of lipopolysaccharide-stimulated B lymphocyte proliferation. Biochem. Soc. Trans. 18:904-905. https://doi.org/10.1042/ bst0180904.

Calder, P. C., and L. E. M. Willemsen. 2016. Immunopharmacology of fatty acids. Eur. J. Pharmacol. 785:1.

Calder, P. C., P. Yaqoob, D. J. Harvey, A. Watts, and E. A. Newsholme. 1994. Incorporation of fatty acids by concanavalin A-stimulated lymphocytes and the effect on fatty acid composition and membrane fluidity. Biochem. J. 300:509-518. https://doi.org/10 $.1042 /$ bj3000509.

Canadian Council on Animal Care. 1993. Guide to the Care and Use of Experimental Animals. Vol. 1. 2nd ed. E. D. Olfert, B. M. Cross, and A. A. McWilliam, ed. CCAC.

Carbonneau, E., A. M. de Passillé, J. Rushen, B. G. Talbot, and P. Lacasse. 2012. The effect of incomplete milking or nursing on milk production, blood metabolites, and immune functions of dairy cows. J. Dairy Sci. 95:6503-6512. https://doi.org/10.3168/jds.2012 $-5643$.

Contreras, G. A., W. Raphael, S. A. Mattmiller, J. Gandy, and L. M. Sordillo. 2012. Nonesterified fatty acids modify inflammatory response and eicosanoid biosynthesis in bovine endothelial cells. J. Dairy Sci. 95:5011-5023. https://doi.org/10.3168/jds.2012-5382.

Fan, Y. Y., D. N. McMurray, L. H. Ly, and R. S. Chapkin. 2003. Dietary (n-3) polyunsaturated fatty acids remodel mouse T-cell lipid rafts. J. Nutr. 133:1913-1920. https://doi.org/10.1093/jn/ 133.6.1913.

Grygiel-Górniak, B. 2014. Peroxisome proliferator-activated receptors and their ligands: Nutritional and clinical implications $-\mathrm{A}$ review. Nutr. J. 13:17.

Hammon, D. S., I. M. Evjen, T. R. Dhiman, J. P. Goff, and J. L. Walters. 2006. Neutrophil function and energy status in Holstein cows with uterine health disorders. Vet. Immunol. Immunopathol. 113:21-29. https://doi.org/10.1016/j.vetimm.2006.03.022.

Hostens, M., V. Fievez, J. L. Leroy, J. Van Ranst, B. Vlaeminck, and G. Opsomer. 2012. The fatty acid profile of subcutaneous and abdominal fat in dairy cows with left displacement of the abomasum. J. Dairy Sci. 95:3756-3765. https://doi.org/10.3168/ jds.2011-5092.

Labouche, C. 1964. La protéinémie chez la vache. Rev. Élev. Méd. Vét. Pays Trop. 17:721-745. https://doi.org/10.19182/remvt.7308.

Lacetera, N., O. Franci, D. Scalia, U. Bernabucci, B. Ronchi, and A. Nardone. 2002. Effects of nonesterified fatty acids and $\beta$-hydroxybutyrate on functions of mononuclear cells obtained from ewes. Am. J. Vet. Res. 63:414-418. https://doi.org/10.2460/ ajvr.2002.63.414.

Lacetera, N., D. Scalia, U. Bernabucci, B. Ronchi, D. Pirazzi, and A. Nardone. 2005. Lymphocyte functions in overconditioned cows around parturition. J. Dairy Sci. 88:2010-2016. https://doi.org/10 .3168/jds.S0022-0302(05)72877-0.

Lacetera, N., D. Scalia, O. Franci, U. Bernabucci, B. Ronchi, and A. Nardone. 2004. Short communication: Effects of nonesterified fatty acids on lymphocyte function in dairy heifers. J. Dairy Sci. 87:1012-1014. https://doi.org/10.3168/jds.S0022-0302(04)73246 -4 .

Le Menn, G., and J. G. Neels. 2018. Regulation of immune cell function by PPARs and the connection with metabolic and neurodegenerative diseases. Int. J. Mol. Sci. 19:1575. https://doi.org/10 .3390/ijms19061575.

LeBlanc, S. J., K. D. Lissemore, D. F. Kelton, T. F. Duffield, and K. E. Leslie. 2006. Major advances in disease prevention in dairy cattle. J. Dairy Sci. 89:1267-1279. https://doi.org/10.3168/jds.S0022 -0302(06)72195-6.

Leroy, J. L., P. Bossaert, G. Opsomer, and P. E. Bols. 2011. The effect of animal handling procedures on the blood non-esterified fatty acid and glucose concentrations of lactating dairy cows. Vet. J. 187:81-84. https://doi.org/10.1016/j.tvjl.2009.10.003.

Martins de Lima, T., R. Gorjão, E. Hatanaka, M. F. Cury-Boaventura, E. P. Portioli Silva, J. Procopio, and R. Curi. 2007. Mechanisms 
by which fatty acids regulate leucocyte function. Clin. Sci. (Lond.) 113:65-77. https://doi.org/10.1042/CS20070006.

McCarthy, M. M., S. Mann, D. V. Nydam, T. R. Overton, and J. A. McArt. 2015. Short communication: Concentrations of nonesterified fatty acids and beta-hydroxybutyrate in dairy cows are not well correlated during the transition period. J. Dairy Sci. 98:62846290. https://doi.org/10.3168/jds.2015-9446.

Moyes, K. M., T. Larsen, N. C. Friggens, J. K. Drackley, and K. L. Ingvartsen. 2009. Identification of potential markers in blood for the development of subclinical and clinical mastitis in dairy cattle at parturition and during early lactation. J. Dairy Sci. 92:5419-5428. https://doi.org/10.3168/jds.2009-2088.

Nicolson, G. L. 2014. The fluid-mosaic model of membrane structure: Still relevant to understanding the structure, function and dynamics of biological membranes after more than 40 years. Biochim. Biophys. Acta Biomembr. 1838:1451-1466. https://doi.org/10 .1016/j.bbamem.2013.10.019.

Nonnecke, B. J., K. Kimura, J. P. Goff, and M. E. Kehrli Jr.. 2003. Effects of the mammary gland on functional capacities of blood mononuclear leukocyte populations from periparturient cows. J. Dairy Sci. 86:2359-2368. https://doi.org/10.3168/jds.S0022 -0302(03)73829-6.

Ollier, S., F. Beaudoin, N. Vanacker, and P. Lacasse. 2016. Effect of reducing milk production using a prolactin-release inhibitor or a glucocorticoid on metabolism and immune functions in cows subjected to acute nutritional stress. J. Dairy Sci. 99:9949-9961. https://doi.org/10.3168/jds.2016-11711.

Ospina, P. A., D. V. Nydam, T. Stokol, and T. R. Overton. 2010. Evaluation of nonesterified fatty acids and beta-hydroxybutyrate in transition dairy cattle in the northeastern United States: Critical thresholds for prediction of clinical diseases. J. Dairy Sci. 93:546-554. https://doi.org/10.3168/jds.2009-2277.

Renner, L., S. Kersten, A. Duevel, H. J. Schuberth, and S. Dänicke. 2013. Effects of cis-9,trans-11 and trans-10,cis-12 conjugated lin- oleic acid, linoleic acid, phytanic acid and the combination of various fatty acids on proliferation and cytokine expression of bovine peripheral blood mononuclear cells. Nutrients 5:2667-2683. https: //doi.org/10.3390/nu5072667.

Ster, C., M. C. Loiselle, and P. Lacasse. 2012. Effect of postcalving serum nonesterified fatty acids concentration on the functionality of bovine immune cells. J. Dairy Sci. 95:708-717. https://doi.org/ 10.3168/jds.2011-4695.

Tsang, W. M., C. Weyman, and A. D. Smith. 1977. Effect of fatty acid mixtures on phytohaemagglutinin-stimulated lymphocytes of different species. Biochem. Soc. Trans. 5:153-154. https://doi.org/ $10.1042 /$ bst0050153.

Vanacker, N., C. L. Girard, R. Blouin, and P. Lacasse. 2020. Effects of feed restriction and supplementary folic acid and vitamin $\mathrm{B}(12)$ on immune cell functions and blood cell populations in dairy cows. Animal 14:339-345. https://doi.org/10.1017/S1751731119002301.

Vanacker, N., S. Ollier, F. Beaudoin, R. Blouin, and P. Lacasse. 2017. Effect of inhibiting the lactogenic signal at calving on milk production and metabolic and immune perturbations in dairy cows. J. Dairy Sci. 100:5782-5791. https://doi.org/10.3168/jds.2017-12570.

Watts, J. S., P. Rezamand, D. L. Sevier, W. Price, and M. A. McGuire. 2013. Short-term effects of dietary trans fatty acids compared with saturated fatty acids on selected measures of inflammation, fatty acid profiles, and production in early lactating Holstein dairy cows. J. Dairy Sci. 96:6932-6943. https://doi.org/10.3168/ jds.2012-6430.

\section{ORCIDS}

Pierre Lacasse @ https://orcid.org/0000-0002-3579-7991 